\title{
viewpoint
}

\section{Who is responsible?}

\author{
Supervisors and institutions need to focus on training in the responsible conduct of research and change \\ the culture in the laboratory
}

Marie-Claude Roland

$\mathrm{O}$ ne important aspect of training students and young scientists is to provide them with core competencies that help them to become successful researchers and prepare for the job market outside research and academia. However, the current paradigm of training through research or for research largely fails to fulfil this requirement. By and large, it focuses on training students for a life in academic research and teaches students little that could be of help later outside academia. To improve the professionalism of staff to support the students' learning experience, the current training paradigm-based on the master-apprentice model_-needs a major overhaul to move towards a model whereby both students and their supervisors cooperate and learn from each other.

\section{In any other arena, the behaviour of supervisors and their virtual malpractice would certainly fall into the category of 'professional misconduct'}

Universities are under more pressure than ever to train graduates with a broader set of skills. Yet, graduate education in the sciences has changed very little. Despite repeated calls for change from the private sector and professional bodies, higher education still focuses largely on preparing young scholars for a career in academia, which can ultimately only offer employment to a minority of today's scientists and engineers. As a result, many young scientists are facing uncertain career prospects and lack a wider range of skills and competencies, which they often cannot or do not learn from their supervisors or university courses.

For many years in Europe, various reports have been calling for changes. In May 2005, the British Government proposed a "universal ethical code for researchers", which, among other things, calls on researchers to "[a]ct with skill and care in all scientific work", to maintain skills and assist their development in others, to "[s] eek to discuss the issues that science raises for society" and to "[l]isten to aspirations and concerns of others" (Council for Science and Technology, 2005). A report prepared in 2001 for the Pew Charitable Trusts (Philadelphia, PA, USA) revealed that doctoral training in the USA did not live up to the expectations of students and did not prepare them for life after their $\mathrm{PhD}$ (Golde \& Dore, 2001). The problem is indeed global and it is the result of the culture, values and traditions that have dominated the scientific community for more than 50 years.

B eyond the obvious mismatch between training and curricula provided by the scientific community and the expectations of employers, there is a more extensive problem with the current way of training young researchers: the master-apprentice model. For many years now, a growing collection of books, reports and articles have lamented the plight of PhD students and postdoctoral researchers in academia and described their mistreatment at the hands of their supervisors. Doctoral students and postdocs have been complaining for years that they are treated as 'extra pairs of hands' or 'cheap labour' and have gone as far as to label some supervisors as 'slave drivers'. In his book, Getting What You Came For: The
Smart Student's Guide to Earning an M.A. or a Ph.D., Robert Peters notes that "[p]roblems with advisers run the gamut, from sexual harassment to academic sabotage" (Peters, 1992). In any other arena, the behaviour of supervisors and their virtual malpractice would certainly fall into the category of 'professional misconduct'. Despite this, things have not changed much since the publication of Peters' book 15 years ago, but citizens are becoming more aware of the situation. A recent article in the French daily newspaper Libération, which compared the life of a PhD student to the 'life of a loser', is just another example in a long series that began many years ago (Buono, 2007).

\section{The attitudes, beliefs and behaviour of researchers who are responsible for training students need to change to reduce the mismatch between training in the research environment and the expectations of society}

Obviously the master-apprentice model, which thrives in the scientific climate (Kuhn, 1962), has its limitations with regard to supporting the development of competencies and promoting the responsible conduct of research. This raises the question whether scientists are really interested in change. How many supervisors actually reflect on how they train their students, their responsibilities as supervisors or how to improve things? Most will just claim that they have no time. Yet supervisors actually get paid to train the next generation of scientists, both as part of their 
salary and as part of the budget detailed in their grants or provided by the university. This 'take the money and run' attitude, which can be seen at all levels of academia and research, is clearly no longer acceptable. This conclusion is reflected by a deluge of charters, recommendations and 'best practice' guides that are distributed as books (Elliott \& Stern, 1997; Resnik, 1998; Shamoo \& Resnik, 2003) or through the websites of organizations such as the US Office of Research Integrity (Rockville, MD, USA) and the Responsible Conduct of Research Education Committee (RCREC; La Jolla, CA, USA), among others. These sites offer guidance, case studies and a wealth of material for supervisors and mentors, but the crucial question is how to implement the recommendations. How can scientists be made accountable for the quality, relevance and efficiency of their training? Should their institutions play a more proactive role? How can we make scientists more aware of their professional responsibility as supervisors?

The concept of the responsible conduct of research (RCR) affects almost every domain of scientific activity: data management, conflicts of interest, authorship, publication, peer-review, collaboration, mentoring and misconduct. Bringing RCR and research ethics back to the forefront of research practices is one way to acknowledge that the current training paradigm is not working well. The attitudes, beliefs and behaviour of researchers who are responsible for training students need to change to reduce the mismatch between training in the research environment and the expectations of society.

$\mathrm{T}$ wo main factors can be cited to explain both this mismatch and the observed weaknesses in the conduct of research itself: the nature of training in academia, and the fierce competition that is slowly destroying the scientific ethos of openness, integrity and quality. Traditional methods of training scientists involve students being the protégés of active scientists, rather than starting as researchers in their own right and taking an active role in their research direction and career. Peters, for example, advises students to "look for an adviser who will initiate you into the mysteries of his art [...] The ideal thesis adviser would [...] help you find a thesis topic, or even find one for you, [...] read your thesis drafts and edit them as needed. He would [...] help you get your first papers published, let you co-author papers

Table 1 | Objectives, skills and values that supervisors should demonstrate

\section{Objectives/skills}

Accredited research supervisors will have shown that they can:

1. Develop a programme of research that is suitable for a research degree

2. Recruit and select an appropriate student for the research programme

3. Plan an appropriate research supervisory process and team

4. Use an appropriate range of teaching and supervisory skills to ensure students' education, attainment and professional development

5. Provide appropriate support to individual students on academic and pastoral issues

6. Use an appropriate range of methods to monitor and assess student progress and attainment

7. Reflect on their own practice, assess and plan for their future needs and continuing development as a research supervisor/research worker

\section{Professional values}

Accredited research supervisors will also have demonstrated:

1. An understanding of situations that support student development and achievement

2. A concern for student progress towards independence

3. A personal commitment to student scholarship, academic excellence and integrity

4. A commitment to work with and learn from colleagues

5. A commitment to and practicing of 'equal opportunities'

6. Continuing reflection on their own professional practice

Source: UK training and accreditation programme for postgraduate supervisors (TAPPS); http://www.iah.bbsrc.ac.uk/TAPPS/

with him [...] and pull the strings necessary to get you a job" (Peters, 1992).

Following this model, the student receives help and assistance but does not have much responsibility, does not acquire competencies beyond research and does not take ownership of his or her career. Furthermore, this system greatly increases the possibility of nepotism and the life-long domination of students who were 'owned' by their supervisor-they will be known as 'John Doe's student' for most of their professional life, even long after 'Doe' has died.

In recent years, several books have described an alternative vision of a 'competent' advisor (Fiske \& Louie, 2000; Cryer, 2006), and some training programmes, particularly in the UK, have been specifically designed to help advisors who are willing to change their practices (Table 1). Yet the traditional image is still dominant because of traditional values and beliefs, and fierce competition within science. I have already described the negative effects of this competition and its consequences on scientific discourse (Roland, 2007), and the same can be said about training.

According to current practices, a young researcher fresh from graduate school should be able to identify his or her research interest and the relevant questions remaining to be answered, become acquainted with the existing tools and methods available in a laboratory — and maybe acquire others - and publish a number of papers over the course of a three-year' PhD programme. An honest supervisor would say that this is a pipe dream, with the consequence that the young trainee will be stuck in a receiving position, rather than proactively developing the competencies to become a good scientist.

\section{...the young trainee will be stuck in a receiving position, rather than proactively developing the competencies to become a good scientist}

However, involving a student in all aspects of research benefits both the supervisor and the student. Designing a research project plays a fundamental role in learning the skills required for structured thinking, knowledge acquisition and elaboration, and strongly contributes to developing autonomy, critical analysis and the capacity to synthesize ideas and experience (Mace \& Pétry, 2000). Such enquiry-based learning provides a trainee with most of the core competencies that they will need for any job. A report by the Boyer Commission on Educating Undergraduates in the Research University (State University of New York; Stony Brook, NY, USA), urges scientists and 
Table 2 | Competencies built during the communication process

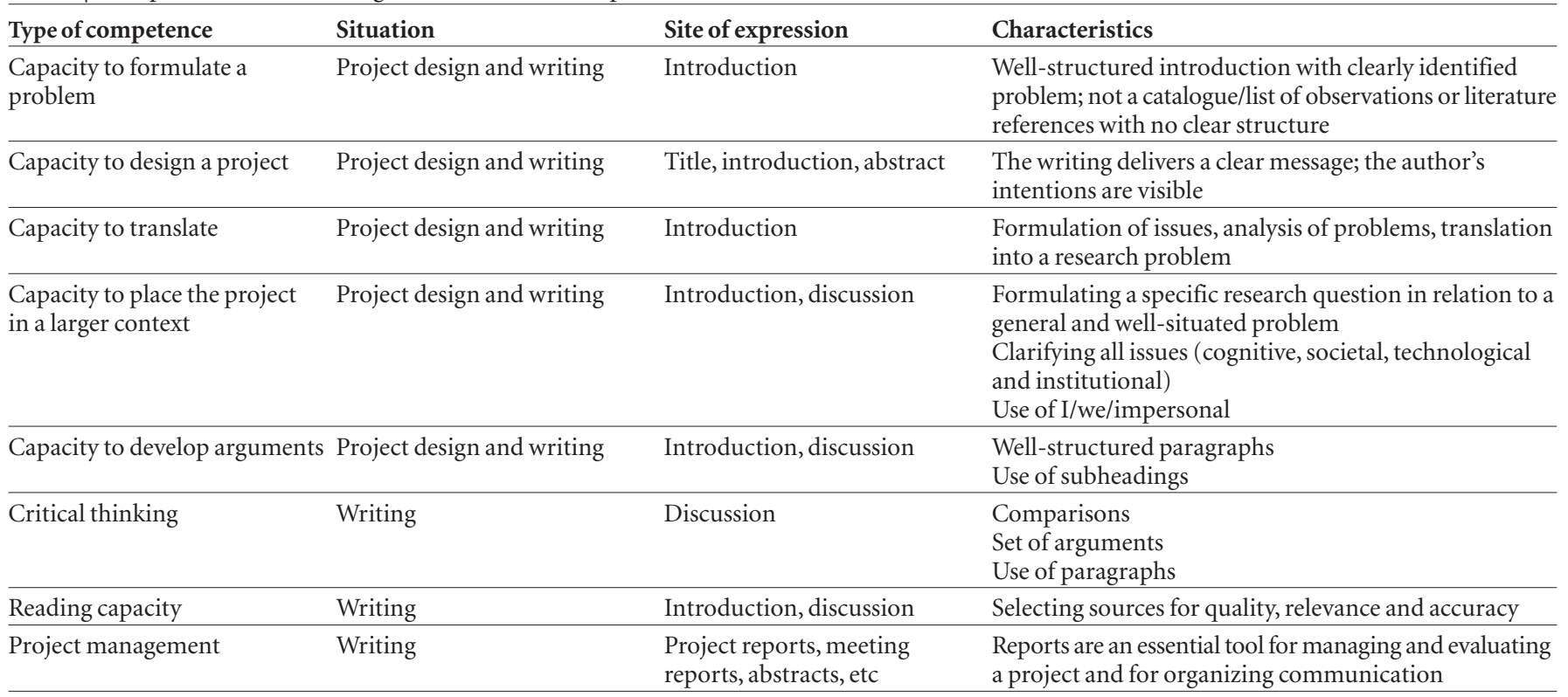

educators to "make research-based learning the standard" and proposes to extend it to all undergraduate studies (Kenny et al, 1998). Similarly, the Centre for Excellence in Enquiry-Based Learning (CEEBL) at Manchester University, UK, argues that this form of learning is "the most natural, creative and enduring method of learning; [it] creates learning situations that replicate those encountered by people in everyday life; [it] is enduring because autonomous control of processes ensures a deep engagement with every stage of learning" (CEEBL, 2006).

\section{One of the most important factors in the quality of research training is the role of the supervisor, who represents a teacher, mentor, role model and sometimes a friend}

At the doctoral level, there is widespread confusion about the difference between a thesis and a research project. The thesis has become a long catalogue of references and descriptions of experiments, rather than the presentation of a well-structured project with clearly formulated questions and objectives, and relevant reflection on the work. I have found that when such confusion ensues, the PhD student is bound to remain a 'receiver' and a 'subject' of their advisor and will rarely become an active, independent enquirer.

Similarly, writing manuscripts plays a crucial role in developing competencies, but most researchers concede that they do not spend enough time on it. Practices vary of course, but many PhD students will just show their results to their supervisors, who then put the manuscript together to save time or because the student has not 'mastered the English language' or 'the art of writing' well enough. In a slightly better scenario, the student will write many drafts of the paper and the supervisor will constantly edit them and ask for changes, without taking the time for further explanations. Such practices are harmful for two reasons: they can lead to misconduct, fraud and plagiarism, and they do not support the development of the student. Communication skills are more than the technical skill of mastering a languagethey are of a cognitive nature and reveal the quality of the research (Table 2).

A $\mathrm{PhD}$ thesis is no longer regarded as only a scholarly piece of work, but is also increasingly seen as a means to support the professional development of an individual. A report for the Nordic Academy for Advanced Study (Oslo, Norway) states that: "The old tradition in research education is apprenticeship. There are still advocates of the view that apprenticeship is not only a part of but the essential element in research training. In contrast, today research training is generally considered as education. [...] Related to this conflict or disagreement are opposing views on what the product of research training is. The old fashioned or traditional view is that the product is the dissertation. Nowadays, both senior scientists and grant-giving bodies assume that the main product is research. In contrast, it can be assumed that the 'product' of research training is a new researcher, or in other words, that the research student is the central person in research training and that the aim of research training is to provide new researchers" (Larsen, 2004).

As mentioned above, the fierce competition that plagues academic research also negatively affects how supervisors treat and train their students. The pressure to publish in order to receive grants or qualify for promotion means that supervisors are increasingly forced to generate as many results as possible and churn out publications. Inevitably this pressure extends to the postdoctoral researchers, PhD students and graduate students. Teaching them how to become good and responsible scientists takes second place to squeezing as much labour out of them as possible.

7 he research community therefore needs to rethink its current training practices and the way that scientific research is conducted. The public-who fund most research through their taxeshave begun to question not only whether researchers are the best people to undertake 
research, but also whether they are the most appropriate people to train the next generation of scientists. Scientists are increasingly asked to follow professional guidelines and to account for the competencies they have acquired and developed as supervisors. However, most scientists are not yet used to this type of accountability and are thus not prepared for it.

If the aim is to train 'highly skilled professionals', and if this is not to become yet more useless terminology, the present situation raises some important challenges for the scientific community. First, both students and their supervisors should identify important skills and competences that should be further enhanced-and this process should be monitored within the scientific community. Second, student training within scholarly institutions should be assessed in terms of widely acknowledged, rigorous criteria, tools and procedures, and not only on the basis of publications and peer committees, as is still common in the scientific community. Third, the achievements of students should not be limited to academic achievements — usually a thesis and published papers - but should also include achievements outside academia.

Achieving these goals will require considerable effort. Improving the quality of supervisor training is the key to changing things within the established culture. One of the most important factors in the quality of research training is the role of the supervisor, who often represents a teacher, mentor, role model and sometimes a friend. However, most supervisors have seldom received any formal training as mentors or teachers. Their skills in this area are often based on their own experiences as students. Researchers absorb unthinkingly —almost unconsciously - the rules, models and traditions of their community, and, once comfortably installed in a paradigm, they rarely question either the theoretical framework or the current practices, and are often resistant to change.

\section{The obvious advantage for supervisors is that by 'outsourcing' these courses, their own research activities do not come under any scrutiny...}

For example, writing about explicit training in research ethics, Deni Elliot and Judy Stern, from the Institute for the Study of Applied and Professional Ethics (Dartmouth
College; Hanover, NH, USA), noted "a substantial gulf between stated importance and activity levels", and reported statements from scientists such as "Only unethical persons have ethical problems; [...] every case is unique, so guidelines are impossible; ethics is merely personal belief; studying ethics doesn't help solve real problems" (Elliott \& Stern, 1997). Such views reflect the fact that many supervisors are not familiar with the content and values of RCR.

Therefore, the first challenge is to convince scientists that being a role model and instructor does not mean expecting the trainee to reproduce the habits and crafts of the community. Training for quality supervision cannot just be reduced to acquiring technical skills, discussing case studies or adopting guidelines. It requires a lifelong commitment to learning and accepting that a supervisor learns from the student, just as the student learns from the supervisor.

$\mathrm{T}$ raining schemes for supervisors should therefore draw from the psychology of appropriation, especially 'epistemological appropriation', in which individuals appropriate the implicit contextual cultural beliefs and epistemologies held by a community. Psychologists have shown that "learning is an on-going process of transaction between individuals and their social contexts" (Hung, 1999). The same author also explored the roles of "self-regulatory processes such as submitting, mirroring and constructing" and "scaffolding, modelling and coaching" in epistemological appropriation, and emphasized the role of social dialogue and self-directed speech. Similarly, research in education shows that critical reflection and explicit articulation of the learning philosophies of both students and instructors can help to "reconcile the misalignments often evident among the expectations, beliefs and practices of instructors and students" (Song et al, 2007). Such insights from these fields can no longer be ignored by supervisors - they increasingly need an understanding of psychology, ethical rules and career development.

The learning model proposed by the Boyer commission is therefore collaborative, rather than competitive: "It assumes that everybody - undergraduate, graduate student, and faculty member alike- is both a teacher and a researcher, that the educational-research process is one of discovery, not transmission, and that communication is an integral part of the shared enterprise" (Kenny et al, 1998). In this regard, in an article about mentoring on the RCREC website, Michael Kalichman wrote: "Taking an active role in helping to train the next generation of scientists should not be optional. The enterprise of science depends on effective communication not just about the science, but about the practice of science, standards of conduct, and ethical and social responsibility. This responsibility for communication extends to all members of the community, not just to senior researchers" (Kalichman, 2002). Similarly, Jacques Hallak and Muriel Poisson, from the International Institute for Educational Planning (Paris, France), recommend that: "to ensure their credibility and ownership, teacher codes of conduct should be established through a participatory process involving the teaching profession. A minimum target to achieve is the organization of awareness-building exercises, information sharing, capacity-building and efforts towards 'mainstreaming participation'" (Hallack \& Poisson, 2007).

\section{Ostensibly, the scientific community continues to protect itself defiantly using self- proclamation as its main weapon}

This is where the ideas of education in the responsible conduct of research (ERCR) and education for sustainable development come together. Both call for a re-orientation of educational approaches-curriculum and content, pedagogy and examinations. Highquality education must be interdisciplinary, holistic and driven by values. It must emphasize critical thinking, problem solving and participatory decision-making.

$\mathrm{T}$ he second challenge is to implement managerial and organizational processes that reduce bad practices and create a virtuous triangle, which "should include a learning environment that values integrity, well-designed governance with effective, transparent and accountable management and a proper system of social control of the way the sector operates and consumes resources" (Hallack \& Poisson, 2007). Many books exist on how to be a good supervisor, and many universities and scientific societies have guidelines and policies to improve the quality of training and supervision at the PhD level. However, simple guidelines cannot solve a problem and a 'policy' alone has no enforcement mechanism. 
Resistance to change is tough and, as the Boyer report explains, is compounded by fragmented curricula and an environment that does not encourage students to actively learn and enquire. "University budgets are now based on the principle of departmental hegemony; as a result, important innovations such as new approaches through interdisciplinarity are often doomed for lack of departmental sponsorship. Departments necessarily think in terms of protecting and advancing their own interests, defined in terms of numbers of faculty, courses, and majors. Initiatives for change coming from sources outside departments are viewed as threats rather than opportunities. New decisions on distributing resources must be carried out at the highest levels in the university, and they can be expected to meet little enthusiasm from those whose interests are protected by existing systems" (Kenny et al, 1998).

It is not surprising that many different strategies designed to tackle the problems in higher education consider research and everything else as almost two separate worlds - the latter often being called the 'real' world. In reality, however, interpersonal and other skills are helpful both within and outside academic research. At many universities, PhD students can attend lectures and periodic examinations of disparate requirements within an academic programme. Similarly, they are encouraged to attend training courses to acquire additional or so-called 'complementary' skills such as communication, project building and project management. Usually, these courses are provided by specialists but they are disconnected from research activities and are therefore less useful and relevant than they could be, which shows that the 'two worlds' must be reconciled.

\section{...institutional resistance to change, and blindly competitive and fragmented environments have destroyed many good ideas and broken much good will}

The obvious advantage for supervisors is that by 'outsourcing' these courses, their own research activities do not come under any scrutiny, which allows practices inside the scientific community to remain unchanged. In my own experience, when I gave writing seminars for PhD students, I

\section{HYPERBOLIC RHETORIC COMMONLY FOUND IN TRAINING PROJECTS}

In order to reach these objectives, the project establishes a collaborative research and training network of network participants and associated partners.

This network gathers expertise in complementary disciplines-for example, molecular biology, cell biology and biochemistry, proteomics and transcriptomics - as well as participants from both the academic and private sectors with an excellent track record of collaborative research. The network also offers a complete range of theoretical, practical and complementary training, as well as scientific workshops. The scientific network will work together with young researchers to develop and implement effective training plans that are tailored to each individual's requirements. Regular meetings, active networking, connections with other scientific projects in the field and with industry will ensure the success of this project and give the recruited researchers an excellent opportunity to reach their career objectives.

Thus, the project has the appropriate size and competence to provide excellent training.

Management and regular evaluation are means of ambition and success.

tried to convince them that writing did not simply amount to reproducing what they had been reading in other papers. I tried to persuade them that good style was synonymous with simplicity and clarity, that they should abandon all jargon and clutter, and that they needed a good research question or hypothesis to deliver a strong message. But I soon discovered that once they returned to the laboratory and were under pressure to spend more time at the bench, or because their supervisor did not see any point in changing habits, the students were unlikely to put any of these recommendations into practice. After that experience, I imposed a rule that I would only work with PhD students and their supervisors simultaneously.

However, what is even worse than an unwillingness to change, is that many research training programmes at universities and many EU-funded projects have adopted the rhetoric about high-quality training and competency enhancement, without actually changing their practicesas the clichés reproduced from project to project show (see sidebar). Ostensibly, the scientific community continues to protect itself defiantly using self-proclamation as its main weapon.

ity is not impossible to improve the quality of training - it can be done by creating and implementing new guidelines and strategies involving faculty, supervisors and PhD students. But it requires extreme tenacity. At the French National Institute for Agriculture (INRA; Paris, France) a team of 30 researchers from all disciplines created an interactive research-training scheme that required the participation of both $\mathrm{PhD}$ students and their supervisors and rested on several hypotheses (http:/www.reflexivesIpr.org). The first hypothesis was that better interaction between $\mathrm{PhD}$ students, their supervisors and career development programmes would enhance the doctoral, postdoctoral and supervisor experience and training process. The second was that working on a research project shared by both the supervisor and the trainee from conception to communication would enhance epistemological appropriation, favour a change in practices and help to develop core competencies. The third was that a participatory approach with full involvement of the faculty and administration would be sustainable and efficient.

The project is currently being evaluated, but it is already clear that although the institution's heads of departments gave full financial support to the scheme, and although the project involved all stakeholders in order to obtain a socially constructed pedagogical innovation, resistance from the institution's power structure has been fierce. I am convinced that this is not the only example where institutional resistance to change, and blindly competitive and fragmented environments have destroyed many good ideas and broken much good will. Nevertheless, no matter how resistant the established community is, and in spite of ingrained practices and beliefs, all stakeholders-in particular the younger generation-must fight for change to adopt RCR in both research and training. I have always been a strong supporter of the idea that training through research could provide young researchers with core competencies needed not only to accomplish their job as researchers, but also for jobs outside research. But I can hardly wait for significant changes in the current paradigm of training. What is at stake is nothing less than the survival of the scientific enterprise. 


\section{REFERENCES}

Buono C (2007) Thésard, vie de loser. 20th March. Libération

CEEBL (2006) Strategic Plan. Manchester, UK: University of Manchester.

www.campus.manchester.ac.uk/ceebl

Council for Science and Technology (2005) Rigour, Respect and Responsibility: A Universal Ethical Code for Scientists. London, UK: Department of Trade and Industry. www.dti.gov.uk

Cryer P (2006) The Research Student's Guide to Success. Milton Keynes, UK: Open University Press

Elliott D, Stern JE (1997) Research Ethics. A Reader. Lebanon, NH, USA: University Press of New England

Fiske P, Louie A (2000) Put your Science to Work: the Take-Charge Career Guide for Scientists. Washington, DC, USA: American Geophysical Union

Golde CM, Dore TM (2001) At Cross Purposes: What the Experiences of Today's Doctoral Students Reveal About Doctoral Education. Philadelphia, PA, USA: The Pew Charitable Trusts Hallack J \& Poisson M (2007) Corrupt Schools, Corrupt Universities: What can be Done? Paris, France: International Institute for Educational Planning

Hung DWL (1999) Activity, apprenticeship, and epistemological appropriation: implications from the writings of Michael Polanyi. Educ Psycho/ 34: 193-205

Kalichman M (2002) Mentoring. La Jolla, CA, USA: Responsible Conduct of Research Education Center. http://rcrec.org

Kenny SS et al (1998) Reinventing Undergraduate Education: A Blueprint for America's Research Universities. Stony Brook, NY, USA: Boyer Commission on Educating Undergraduates in the Research University

Kuhn TS (1962) The Structure of Scientific Revolutions. Chicago, IL, USA: University of Chicago Press

Larsen PO (2004) Quality in Research Training, Nordic Cooperation on Quality Assessment of Research Training. Oslo, Norway: Nordic Academy for Advanced Study (NorFA)

Mace G, Pétry F (2000) Guide d'Élaboration d'un Projet de Recherche 2nd edn. Laval, France: Presses de l'Université de Laval

Peters RL (1992) Getting What You Came For: The Smart Student's Guide to Earning an M.A. or a Ph.D. New York, NY, USA: Farrar, Straus \& Giroux

Resnik DB (1998) The Ethics of Science; An Introduction (Philosophical Issues in Science). London, UK: Routledge

Roland MC (2007) Publish and perish: hedging and fraud in scientific discourse. EMBO Rep 8: $424-428$
Shamoo AE, Resnik DB (2003) Responsible Conduct of Research. Oxford, UK: Oxford University Press

Song L, Hannafin M, Hill J (2007) Reconciling beliefs and practices in teaching and learning. Educ Tech Res Dev 55: 27-50

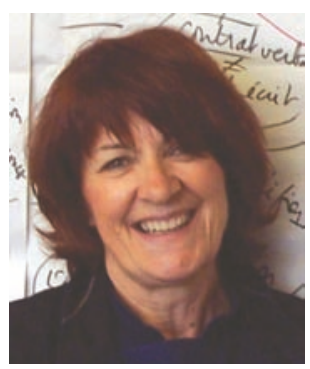

Marie-Claude Roland is Director of Linguistics \& Research Practices at the French National Institute for Agricultural Research in Paris, France.

E-mail: roland@paris.inra.fr

doi:10.1038/sj.embor.7401035 